\section{Evangelical medical ethics: a review article}

Some issues of medical ethics have always been of concern to Christians because they involve crucial questions of the life, health and death of human beings. In the United Kingdom there are at the moment two Christian bodies specifically concerned with the study of medical ethics and publishing their findings. One is the recently founded Linacre Centre, a Roman Catholic foundation (which ought to be the subject of an article in this journal), and the other the longer established Christian Medical Fellowship (CMF), an inter - denominational evangelical group (which is the subject of this article). Readers of the fournal of medical ethics need to pay attention to both, partly because in a plural society one must take account of all significant ethical stances, and even more because the Judaeo-Christian tradition has had such a formative influence in our culture, has much to commend it, and still has much residual influence.

An evangelical stance is generally associated with stress on the Bible, not necessarily in a 'fundamentalist' sense (though often in the past it has been, and to some extent still is). Doctrinally it tends to stress the depravity more than the dignity of man; and to adopt among the various doctrines of the atonement which have arisen and persisted in the Church (none of which has attained general acceptance) the one commonly called 'penal substitution' according to which Christ suffered punishment vicariously for man. On ethical questions evangelicals wish if possible to produce clear, Biblical rulings.

It is with these characteristics in mind that I reflect on fifteen pamphlets published since 1975 by the CMF. All of them are indeed reflected in these pamphlets, but the chief impression that emerges is that they are well on their way towards emancipation from a wooden use of Scripture. However the pessimistic view of man leads them to undervalue human thinking derived from sources other than the Bible, whether other religions or philosophies, and always to refer negatively to humanism. In particular (unlike the Linacre Centre papers) the tradition of moral philosophy is either ignored or treated vaguely, so that fundamental problems in making moral choices which are common to Christians and others are not faced; for instance, how far they should be made on a deontological and how far on a teleological basis. A further reason for this is probably the desire to arrive at uniquely Christian insights.

I will illustrate these points by some examples. With regard to the Bible the questions of leprosy and faith healing are significant. Leprosy is an important issue to evangelicals because of its prominence in the Old Testament and the Gospels and the stigma attached to it, and its relation to work among lepers today where Christians are only part of a concerted effort. Immediately, problems of Biblical translation of medical terms are involved. If, as seems possible, modern leprosy is not the same as Biblical leprosy, the Christian ministry to lepers is none the less a divine task, but it is not a literal following of Jesus; moreover in spite of the dominical command in the gospels there is no record in the New Testament of the early Christians actually cleansing lepers. S G Browne's pamphlet reaches the important conclusion that the Scriptural command to 'cleanse the leper' should mean to us 'Seek the outcast, the under-privileged, all those who suffer because of society's attitudes. Help them in all ways. Help to put them on their feet, and bring them back into the society that despised and ostracised them'. ${ }^{9}$ These are wise and radical words. Browne says they are a paraphrase (which under-states their extension of the text) and that they have the 'same content' (which clearly they do not). Remnants of Biblicism lie behind this claim.

As to faith healing, the tendency is to take the Biblical narratives fairly literally, particularly St John's Gospel, but 'miracles' are practically speaking confined to Biblical times. It is stressed that ' $G o d$ has authority and power to intervene by miracle at any time', ${ }^{10}$ but in practice as sceptical a position is taken over alleged miraculous cures, including charismatic healing claims, as the most positivisticly minded medical man is likely to take. Signs and wonders may happen occasionally, but we are not to expect them. In particular we are not to equate sickness with sin and healing with conversion. ${ }^{12}$ Let the doctor and the pastor each stick to his last. There is force in this, but the dichotomy may be too sharp.

When we turn to moral philosophy the belittling of this is most evident in the pamphlet by Crouch. ${ }^{4}$ She moves quickly from ethics to Christian ethics because of an entirely negative attitude towards humanism. (The London Medical Group is criticised as tending to produce moral confusion by paying attention to ethical stances other than the Christian one). There is a brief but confused passage on natural law and basic moral insights, which she says are supposed to be 'independent of conscience'. This in her mind condemns them because they are not related to an external authority or revelation. Traditional Christian wisdom, however, takes this internal forum of conscience very seriously. Gardner, ${ }^{5}$ similarly, moves uncertainly at this point, being inclined to confuse conscience with conscientiousness. Crouch ${ }^{4}$ wants leadership, directive counselling and the teaching of underlying moral principles. It is not clear what she has in mind; the problem comes, however, with 'applying' such principles to particular issues, as these pamphlets themselves bear 
witness. Smith advocates listening more than prescribing in the course of an impressive account of how a christian group in Sheffield moved from concentrating on helping the drug-dependent to the selfpoisoners, glossing none of the difficulties. Smyth ${ }^{14}$ says that 'to possess the mind of Christ is not to have clear answers but humility in seeking them'. In McAllister's ${ }^{11}$ treatment of the relatively recent recognition of alcoholism as a disease, which he welcomes, the old evangelical rule of abstinence (miscalled temperance) is not mentioned.

In view of the prescriptive tone of the writing the general absence of clear rulings is welcome. My impression is that the medical competence of the writers has triumphed over doctrinal pre-suppositions. Perhaps they give up too soon because to wrestle further with the complexities of moral decision in particular cases might raise a query about the specifically Christian nature of their position which they are anxious to stress. Abortion and euthanasia worry them, as indeed they worry many others, but talk of the absolute value of human life 14 does not resolve urgent questions of social priorities or of the conflicting claims of life with life.

Medical competence leads the writers also to draw attention to problems insufficiently faced, certainly by Christian opinion, such as the growing volume of chronic degenerative illness and the possibility of do-it-yourself abortion within a decade, but they do not develop the discussion of these.

Two other tendencies in the pamphlets call for mention. One is a certain individualism which leads to difficulty with the vexed questions of vocation versus those of professionalism in the context of the structures of operation of the NHS. This individualism is probably not endemic to the evangelical position but more 'culture bound', since western evangelicalism has been so much part of an individualist capitalist culture; some evangelical Christians in eastern Europe, Hungary for instance, take a different line. The suspicion of other ethical stances is not thought out in terms of a plural society, and seems to indicate that implicitly many of the authors are still assuming the old 'Christendom' position, mistaking the outward structures of the Church of England and the Church of Scotland for the reality. The other tendency is a certain fear of man's greater control over the details of his life, especially over his medical situation, as if this in some way diminishes God's authority. No thoughts of man as cocreator with God can be discerned here. Perhaps this is not unlike the common evangelical suspicion of the visual arts as a distraction from concentration on God.

The pamphlets are well and impressively produced; and the steady production of them is admirable. One is left with the judgment that the peculiarly evangelical Biblical and doctrinal positions are not decisive for the contents, that they should not preclude cooperation with those of different persuasion, and that everyone would gain by more cross-fertilisation of ideas between Christians working in this field.

\section{The books reviewed}

${ }^{1}$ Christian Ethics and Medical Practice: an affirmation (1975) n.p.

${ }^{2}$ Our Priorities (1976) D P Burkit. 20p.

${ }^{3}$ The Challenge of Medical Education (1976) M M Webb-Peploe 2op.

${ }^{4}$ Imparting Ethics to Medical Students (I977) Muriel Crouch. 25p.

${ }^{5}$ By What Standard? (1977) R F R Gardner. 30p.

${ }^{6}$ The Future of Professional Freedom (1977) Roland R Winton. 25p.

${ }^{7}$ The Place of Faith in Medical Practice (1978) J Stuart Horne. 25p.

${ }^{8}$ Medicine as a Vocation (1978) David Short. 25p.

'Leprosy in the Bible (1979) S G Brown. (3rd rev. \& enlarged edn.) 6op.

${ }^{10}$ Some Thoughts on Faith Healing (1979) V Edmunds \& G Scorer (fI.00).

${ }^{11}$ The Problem of Alcohol (1979) W T B McAllister. 3op.

12Healing: biblical, medical and pastoral (1979) G Scorer. 35p.

${ }^{13}$ The Overdose (I979) A J Smith. 3op.

${ }^{14}$ The Value of Human Life (1979) Harley Smyth. 25p.

${ }^{15}$ Legalised Abortion: the continuing dilemma (1979) Gordon M Stirrat. 30p.

(All published by Christian Medical Fellowship from I57 Waterloo Road, London, SEI 8XN.)

RONALD PRESTON
Bibliography of Bioethics

Volume 5, LeRoy Walters (Ed). Gale Research Co, Detroit, 1979, 334pp. \$44

The systematic study of medFeal ethics and of the broader field when the Americans call bioethics, ispa relatively recent phenomenon, هso despite its exponential growth oyer the past two decades it may sefem rather excessive to have two regllarly published bibliographies devoted to its literature. Nevertheless, we are blessed with two - produets of American-style competition (高d cooperation) between the Hastipgs Center (otherwise known as the Institute of Society, Ethics and ithe Life Sciences, at Hastings on Hudson) and the Center for Bopethics, Kennedy Institute, Georgetown University.

The first, the Bibliography $\mathbb{\complement}_{\circ}$ Society, Ethics and the Life Scienges, has been produced annually for the past decade and has been availaBle in a handy magazine format. Under a limited number of subject headings relevant books and articles have been listed alphabetically according Gto author. Until five years ago ine had to be content with this guide the current literature in Engligh. With the appearance of the moch more comprehensive Bibliography of Bioethics, produced by the Kennedy Institute, the whole scene $\overrightarrow{B a s}$ changed. Computers have caught $\overline{\mathrm{z}} \mathrm{p}$ with the amateurs in the field and now everyone has to look to their laurels if the quality of scholars is to match the professional standiard set by this analytical compendium. This series of volumes is intendedito be the definitive bibliographical index of material on the subject and ro library, public or private, with -an investment in medical ethics gisn afford to be without it.

Volume 5 of the Bibliographynof Bioethics covers 1,601 documents published from 1973 through $198 \%$, (with the majority of those publishffed in 1977). Like previous volumesin the series, it covers a variety of for ins of published documents, ranging from books to court decisions, newsspaper articles to serious academic papers. Material has been culled from no less than 82 periodiogls representing such diverse fields ass medicine, psychology, religiकh, philosophy and political scienge. Each volume is arranged in six sections: Introduction, List $\varnothing \mathrm{f}$ Journals cited, Bioethics Thesaures, 